\title{
Death of a Himalayan Vulture in South India highlights the potential threat of power infrastructure.
}

\author{
S. Manigandan ${ }^{1}$, P. Kannan ${ }^{1}$, H. Byju ${ }^{2}$, S. Bharathidasan ${ }^{3}$, Cimi Thambi ${ }^{1} \&$ B. Ramakrishnan ${ }^{1 *}$ \\ ${ }^{1}$ Department of Zoology and Wildlife Biology, Government Arts College, Udhagamandalam, The Nilgiris, Tamil Nadu, India \\ ${ }^{2}$ Independent researcher, No.35, Rakatchi Garden, Ganapathy P.O., Coimbatore, Tamil Nadu, India \\ ${ }^{3}$ Arulagam, Ellappalayam P.O., Coimbatore, Tamil Nadu, India
}

*Corresponding author: bio.bramki@gmail.com

http://dx.doi.org/10.4314/vulnew.v80i1.3

The Mudumalai Tiger Reserve (MTR) in South India holds four resident species of vultures in the Nilgiri Biosphere Reserve, on the northern flank of the Nilgiri Mountain Ranges in the southern Western Ghats (Samson et al. 2016). Three vulture species considered as scarce migrants in South India have also been recorded in MTR: Himalayan Vulture Gyps himalayensis (Praveen et al. 2014), Cinereous Vulture Aegypius monachus (Samson et al. 2019) and Eurasian Griffon Gyps fulvus (Gajamohan 2020), typically occurring from October to February as winter visitors.

At $10 \mathrm{~h} 30$ on 19 January 2020, we found a dead juvenile Himalayan Vulture (Figure 1) near Maravakandy hydroelectric powerhouse

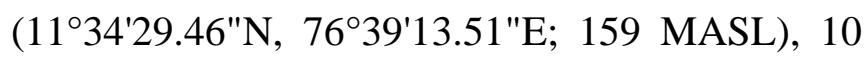
$\mathrm{km}$ from where a juvenile Himalayan Vulture was observed and photographed two days earlier. The dead vulture was found on the ground in the vicinity of two power lines (one $230 \mathrm{~V}$ line and one $11 \mathrm{kV}$ line), $4 \mathrm{~m}$ from the base of a pole supporting the smaller line (Figure 2). A possible cause of death was electrocution, indicated by an odour of recent burning when the vulture was found. However, following the suggestion made by Kagan (2016) that, "a necropsy is necessary to make a diagnosis", the definite cause of death could not be determined because a necropsy examination was not done due to a lack of veterinary specialists and necessary resources. We informed the Forest Department and they removed the dead bird for disposal.

The lack of primary information about the negative impacts of power lines on birds in India has been raised as a cause for concern (Uddin et al. 2021), with Botha et al. (2017) stating that, "there is currently little documented evidence" about the threat posed by power lines to vultures in Asia. However, in Jodphur in north-west India, electrocution was identified as a notable cause of mortality of vultures, including Himalayan Vultures (Saran \& Prohit 2012), and Chaudhary et al. (2019) considered electrocution as one of the top threats to vulture populations in neighbouring Nepal. Although it is not supported by firm evidence from a necropsy, this photographic record is, to our knowledge, the first record of a Himalayan Vulture suspected to have been killed by electrocution in South India.

Given the ongoing expansion of the electricity network in India, the installation of non-lethal infrastructure and retrofitting of existing structures are needed to reduce the risk of electrocution of vultures and other birds (Uddin et al. 2021). To inform the implementation of suitable mitigation strategies, a proactive and systematic approach to assess the rates of bird mortality caused by power lines is needed, particularly in areas such as MTR which are known to be important for vultures and 
other at-risk species. In addition, the adoption of veterinary personnel will facilitate the standardized protocols for necropsy examinations determination of causes of mortality (Kagan 2016), and providing suitable training and resources for further informing conservation measures.

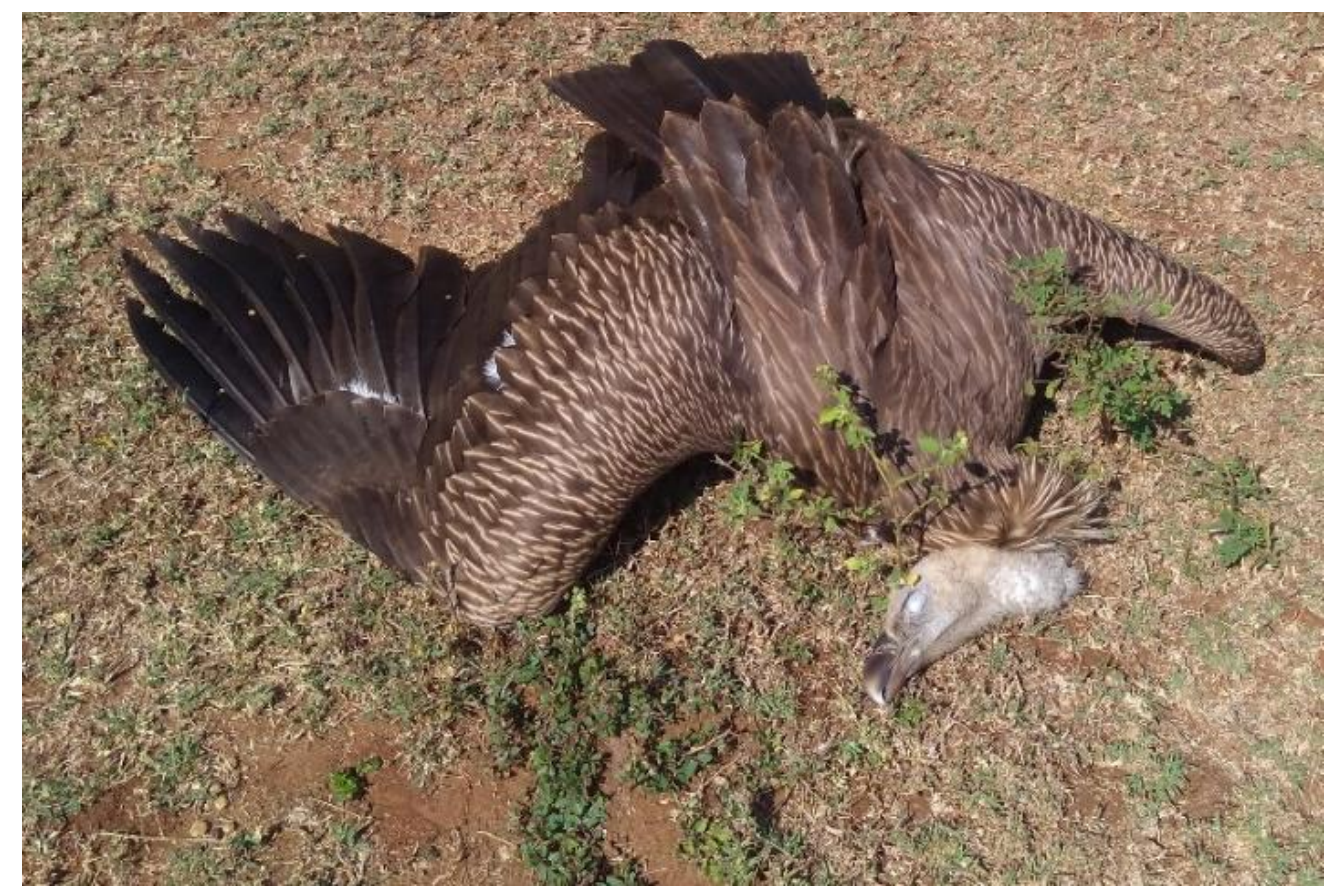

Figure 1: A dead juvenile Himalayan Vulture found on 19 January 2020 near Maravakandi powerhouse in the Mudumalai Tiger Reserve, Tamil Nadu, India. Although there were no clear visual signs of electrocution and no necropsy was completed, an odour of burning indicated electrocution as a possible cause of death. (Photo: SM).

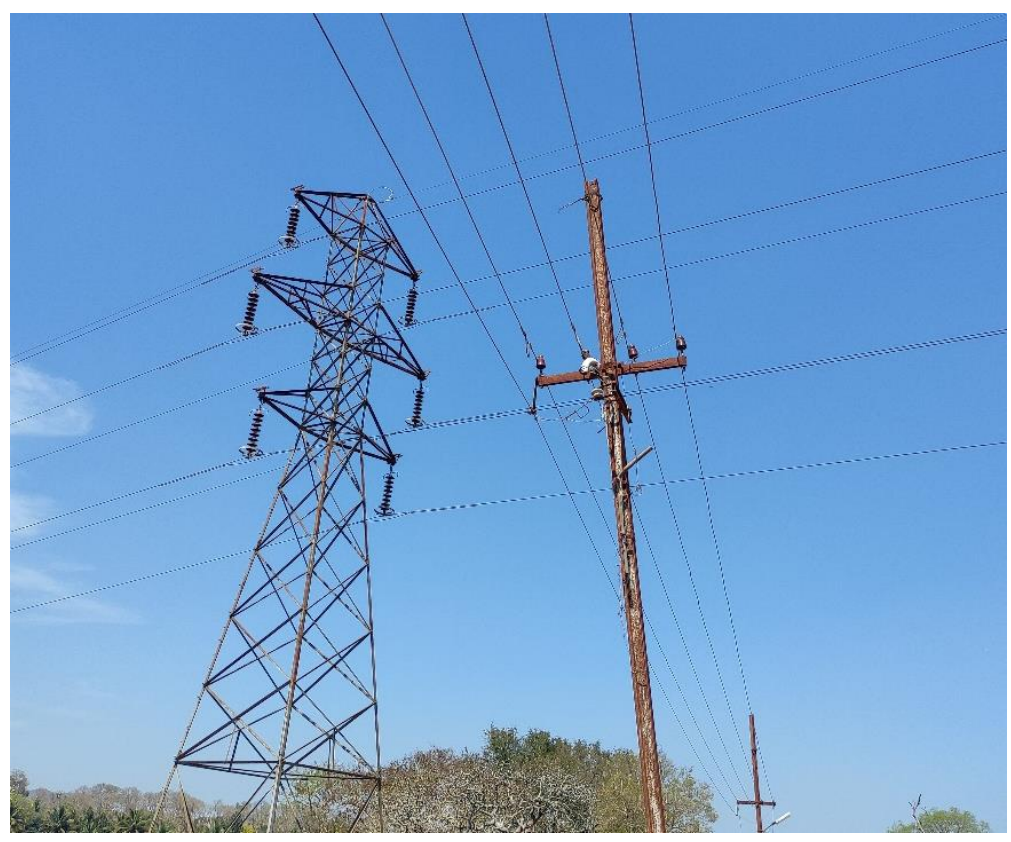

Figure 2: Power lines $(230 \mathrm{~V}$ and $11 \mathrm{kV})$ and poles at the site where the Himalayan Vulture was found dead, $4 \mathrm{~m}$ from the base of the smaller pole (Photo: BR) 


\section{Acknowledgements}

We would like to acknowledge the Tamil Nadu Forest Department for giving necessary permission (Ref. No. WL5(A)/ 2816 /2017 Permit No. 07/2017 dated 25/01/2017). We thank all the staff of Mudumalai Tiger Reserve, particularly Mr Venkatesh, IFS, Field Director, and Mr Arunkumar, Deputy Director, Masinagudi Division, for issuing necessary permission to carry out our fieldwork; and the Forest Range Officers, Mr Murali (Segur Range), Mr Mariappan (Masinagudi Range) and Mr Kandan (Singara Range) for providing all logistics. We are grateful to the editors and Dr Chris Bowden of RSPB and SAVE for reviewing and making valuable suggestions to improve the manuscript.

\section{References}

Botha, A. J., Andevski, J., Bowden, C.G.R., Gudka, M., Safford, R.J., Tavares, J. \& Williams, N.P. (2017). Multi-species Action Plan to Conserve African-Eurasian Vultures. CMS Raptors MOU Technical Publication No. 5. CMS Technical Series No. 35. Coordinating Unit of the CMS Raptors MOU, Abu Dhabi, United Arab Emirates.

Chaudhary I.P., Dangaura, H.L., Rana, D.B., Joshi, A.B., \& Bhusal, K.P. 2019. What are the threats to vultures other than NSAIDs in Nepal? Vulture Bulletin 8: 41-43.

Gajamohanraj, D. 2020. A Griffon Vulture Gyps Fulvus from Moyar valley, Masinagudi, Tamil Nadu. Indian Birds 16: 160-161.

Kagan, R.A. 2016. Electrocution of raptors on power lines: A review of necropsy methods and findings. Veterinary Pathology 53(5): 1030-1036.

Praveen, J., Nameer, P.O., Karuthedathu, D., Ramaiah, C., Balakrishnan, B., Rao, K.M., Shurpali, S., Puttaswamaiah, R., \& Tavcar, I. 2014. On the vagrancy of the Himalayan Vulture Gyps himalayensis to southern India. Indian Birds 9: 19-22.

Saran, R.P. \& Prohit, A. 2012. Eco-transformation, and electrocution. A major concern for the decline in vulture population in and around Jodhpur. International Journal of Conservation Science 3(2): 111118.

Samson, A., Ramakrishnan, B., Veeramani, A., \& Ravi, P. 2016. Population status and habitat preference of vultures in Mudumalai Tiger Reserve, Tamil Nadu, Southern India. Podoces 11: 7-12.

Samson, A., Ramakrishnan, B., Selvan, V., \& Manigandan, S. 2019. Cinereous Vulture Aegypius monachus in Mudumalai Tiger Reserve, Western Ghats, and its status in southern India. Indian Birds 15: 93-94.

Uddin, M., Dutta, S., Kolipakam, V., Sharma, H., Usmani, F., \& Jhala, Y. 2021. High bird mortality due to power lines invokes urgent environmental mitigation in a tropical desert. Biological Conservation 261: 109262. 